\title{
Coautoria institucional na produção científica brasileira sobre hanseníase: uma análise a partir da base de dados Web of Science
}

\author{
Institutional co-authorship in Brazilian scientific production on leprosy: \\ an analysis based on the Web of Science database
}

\section{Coautoría institucional en la producción científica brasileña sobre lepra: un análisis de la base de datos Web of Science}

\author{
Andréa Cristina Bogado ${ }^{1, a}$ \\ andrea.bogado@unesp.br | https://orcid.org/0000-0002-6383-8738
}

Fabio Sampaio Rosas ${ }^{2, b}$

fabio.rosas@unesp.br | http://orcid.org/oooo-0002-7044-1683

Maria Cláudia Cabrini Grácio ${ }^{1, c}$

cabrini.gracio@unesp.br | https://orcid.org/0000-0002-8003-0386

\footnotetext{
${ }^{1}$ Universidade Estadual Paulista, Faculdade de Filosofia e Ciências. Marília, SP, Brasil.

2 Universidade Estadual Paulista, Faculdade de Ciências Agrárias e Tecnológicas. Dracena, SP, Brasil.

a Especialização em Gestão e Uso da Informação em Saúde pela Universidade Santo Amaro.

b Doutorado em Ciência da Informação pela Universidade Estadual Paulista.

c Doutorado em Filosofia pela Universidade Estadual de Campinas
}

\section{RESUMO}

A colaboração científica entre pesquisadores, instituições e países tem despertado o interesse de estudiosos da ciência da informação que desejam conhecer as relações estabelecidas entre os atores envolvidos, a dinâmica e a evolução dos padrões sociais na comunicação científica. Por meio de análise bibliométrica, este estudo objetiva visualizar a rede de colaboração científica entre a comunidade discursiva que conduz pesquisas sobre hanseníase no Brasil, por meio das relações de coautoria institucional. As características da colaboração foram estudadas a partir da coautoria de 498 artigos indexados na base de dados Web of Science no período de 2016 a 2020. As análises revelam que parte significativa dos artigos foi publicada por um grupo reduzido de instituições e que as universidades, apesar de maior número, possuem publicações mais pulverizadas e não ocupam a centralidade da rede, que é dominada por institutos de pesquisa, que concentram grande número de publicações em poucas unidades.

Palavras-chave: Colaboração científica; Coautoria; Análise de domínio; Análise de redes sociais; Hanseníase.

\section{ABSTRACT}

Scientific collaboration between researchers, institutions and countries has aroused the interest of Information Science scholars who want to know the relationships established between the actors involved, the dynamics and evolution of social standards in scientific communication. Through bibliometric analysis, this study aims to visualize the network of scientific collaboration between the discursive community that 
conducts research on leprosy in Brazil through institutional co-authoring relationships. Collaboration characteristics were studied based on the co-authorship of 498 articles indexed in the Web of Science database in the period 2016-2020. The analyzes reveal that a significant part of the articles was published by a small group of institutions and that, despite the greater number, the universities have more widely distributed publications and don't occupy the centrality of the network, which is dominated by research institutes, which concentrate a large number of publications in a few units.

Keywords: Scientific collaboration; Co-authorship; Domain analysis; Social networks analysis; Leprosy.

\section{RESUMEN}

La colaboración científica entre investigadores, instituciones y países ha despertado el interés de los estudiosos de las Ciencias de la Información que quieren conocer las relaciones que se establecen entre los actores involucrados, la dinámica y evolución de los estándares sociales en la comunicación científica. A través del análisis bibliométrico, este estudio tiene como objetivo visualizar la red de colaboración científica entre la comunidad discursiva que realiza investigaciones sobre la lepra en Brasil a través de relaciones institucionales de coautoría. Las características de la colaboración fueran estudiadas a partir de la coautoría de 498 artículos indexados en la base de datos de Web of Science en el período de 2016 hasta 2020. Los análisis revelan que una parte importante de los artículos fue publicada por un grupo reducido de instituciones y que las universidades, aunque en mayor número, tienen publicaciones más dispersas y no ocupan la centralidad de la red, que es dominada por institutos de investigación, que concentran un gran número de publicaciones en pocas unidades.

Palabras clave: Colaboración científica; Coautoría; Análisis de dominio; Análisis de redes sociales; Lepra.

Este artigo compõe o dossiê Estudos métricos da informação científica em saúde, parte 2.

Contribuição dos autores:

Concepção e desenho do estudo: Andréa Cristina Bogado e Maria Cláudia Cabrini Grácio.

Aquisição, análise ou interpretação dos dados: Andréa Cristina Bogado.

Redação do manuscrito: Andréa Cristina Bogado, Maria Cláudia Cabrini Grácio e Fábio Sampaio Rosas.

Revisão crítica do conteúdo intelectual: Maria Cláudia Cabrini Grácio e Fábio Sampaio Rosas.

Declaração de conflito de interesses: não há.

Fontes de financiamento: não houve.

Considerações éticas: não há.

Agradecimentos/Contribuições adicionais: não há.

Histórico do artigo: submetido: 17 maio 2021 | aceito: 12 out. 2021 | publicado: 25 fev. 2022.

Apresentação anterior: não houve.

Licença CC BY-NC atribuição não comercial. Com essa licença é permitido acessar, baixar (download), copiar, imprimir, compartilhar, reutilizar e distribuir os artigos, desde que para uso não comercial e com a citação da fonte, conferindo os devidos créditos de autoria e menção à Reciis. Nesses casos, nenhuma permissão é necessária por parte dos autores ou dos editores. 


\section{INTRODUÇÃO}

A hanseníase é uma doença dermatológica, crônica, infectocontagiosa e que acomete principalmente os nervos periféricos do doente, podendo levar a uma série de incapacidades físicas. No Brasil, é considerada uma doença de notificação compulsória e de investigação obrigatória pelo Ministério da Saúde (BRASIL, 2002).

Ferreira (2014) aponta que a hanseníase se encontra no grupo de doenças tropicais negligenciadas (DTN), caracterizadas por estarem associadas a regiões onde a população vive em condições de pobreza e apresentam precárias condições de vida, que contribuem para a manutenção do quadro de desigualdades sociais e representam um obstáculo ao crescimento dos países em desenvolvimento.

No início da década de 1940, foi adotado o tratamento quimioterápico que levou à descoberta da cura da hanseníase. Esse tratamento continua em uso até os dias atuais e trata-se de uma combinação de três drogas antibióticas, conhecida como poliquimioterapia (PQT). O tratamento da hanseníase é ambulatorial, devendo ser realizado nas unidades básicas de saúde, e encaminhado para centros de complexidade, quando necessário (CASTORINA-SILVA, 2013). Quando não diagnosticada precocemente e tratada, tende a evoluir para formas mais agressivas da doença, com alto potencial de incapacidade física e de sequelas sociais, econômicas e psicológicas.

Em 2016, a World Health Organization (WHO) publicou o documento Global Leprosy Strategy 2016-2020: accelerating towards a leprosy-free world, com o objetivo de “[...] reduzir ainda mais o ônus da hanseníase, proporcionando cuidados mais abrangentes e oportunos seguindo os princípios de equidade e justiça social" (tradução nossa), tendo em foco a diminuição de novos casos da doença e, assim, alcançar a sua erradicação (WORLD HEALTH ORGANIZATION, c2017, p. 9). Entre as diversas ações previstas para a área da saúde que buscam alcançar o objetivo proposto, está a "Ênfase em pesquisas para apoiar o controle da hanseníase" (p. 10), orienta as nações a apoiarem a pesquisa básica em hanseníase nos países endêmicos, a fim de estudar sua transmissão, desenvolver novas ferramentas de diagnóstico, aplicar esquemas profiláticos e investir em novas pesquisas terapêuticas (WORLD HEALTH ORGANIZATION, c2017).

Em abril de 2021, a WHO realizou a atualização do documento, desenvolvido por meio de um amplo processo consultivo entre os gerentes dos programas nacionais de hanseníase no mundo, nas agências técnicas, envolvendo especialistas em saúde pública, agências de fomento e pessoas diretamente afetadas pela hanseníase, durante os anos de 2019 e 2020. O documento intitulado Towards zero leprosy: global leprosy (hansen's disease) strategy 2021-203o visa alcançar a eliminação definitiva da hanseníase no mundo e está estruturado em quatro pilares. No primeiro pilar, "Implementar roteiros integrados de zero hanseníase em todos os países endêmicos", um dos objetivos principais está no incentivo à pesquisa:

Governos, instituições acadêmicas, setor privado, ONGs locais e internacionais, líderes comunitários e organizações da sociedade civil, incluindo organizações de pessoas afetadas pela hanseníase [...] devem colaborar na pesquisa básica e operacional para a construção de uma base de evidências cuja finalidade seja melhorar as políticas, as estratégias e os programas nacionais de combate à doença. (WORLD HEALTH ORGANIZATION, c2021, p. 15, tradução nossa).

Segundo a WHO (2020), a redução do número de novos casos de hanseníase no mundo é gradual e tem sido uniforme nos últimos 10 anos. No entanto, Índia, Brasil e Indonésia são os países com as maiores taxas de incidência da doença. Sobral (2019) aponta que, de acordo com a WHO, há uma relação de causa e efeito entre o sucesso das soluções relacionadas às DTN e o investimento em ciência e pesquisa.

Ao remontar o histórico dos estudos sobre DTN no Brasil, Sobral (2019) aponta que os primeiros registros datam do século XIX, quando um grupo de médicos brasileiros, na intenção de definir e valorizar 
o meio tropical em que viviam, criou a primeira revista médica brasileira, que ia na contramão da medicina praticada pelo império e priorizava as pesquisas voltadas às doenças tropicais que acometiam a população, buscando, assim, criar uma tradição brasileira em medicina. Em outro momento, o autor relata que diversos estudos realizados nas últimas décadas apontaram o Brasil como um dos maiores produtores de estudos sobre medicina tropical, figurando em terceiro lugar entre os países mais produtivos no ranking da base de dados Web of Science em 2016.

Assim, reconhecendo a importância e a relevância dos estudos sobre DTN na produção científica brasileira e tomando a questão da hanseníase como um atual problema de saúde pública no Brasil, torna-se necessária a condução de estudos que busquem compreender a produção científica nacional acerca do tema, elucidando como a comunidade científica, constituída pelos autores e pelas instituições, tem conduzido suas pesquisas na descoberta e divulgação de novas informações que contribuam para a formulação de políticas públicas e ações efetivas para o alcance da meta global de eliminação da hanseníase.

Na literatura sobre DTN, os estudos métricos são cada vez mais presentes, a exemplo dos trabalhos publicados por Alves, N. L. (2018); Bender et al. (2015); Falagas, Karavasiou e Bliziotis (2006); Fontecha, Sánchez e Ortiz (2021); Glover e Bowen (2004); Jardim et al. (2020); Schoonbaert e Demedts (2008); Sobral (2019) e Sobral et al. (2016). Dos trabalhos citados, somente dois estudos tratam sobre métricas da produção científica brasileira em hanseníase, a saber: Alves, N. L. (2018) e Jardim et al. (2020). O primeiro realizou um estudo cientométrico para análise do desenvolvimento das produções e do conhecimento científico sobre hanseníase, no período de 1997 a 2016. No segundo, os autores utilizaram estudos bibliométricos para analisar a produção científica relacionada à hanseníase no Brasil no período de 2000 a 2019. Destacase que, em ambos, a coleta de dados foi realizada na base de dados Web of Science. Perante o exposto acerca da busca na literatura sobre DTN, podemos inferir a escassez de estudos métricos que tomam como objeto da pesquisa a produção científica brasileira em hanseníase, corroborando a importância deste trabalho.

Assim, esta pesquisa objetiva analisar a produção de artigos científicos brasileiros de visibilidade internacional sobre hanseníase no período de 2016 a 2020, tomando a Web of Science como base representativa da ciência. De forma mais específica, busca caracterizar: o tipo de autoria que deu origem ao conhecimento disseminado nos artigos brasileiros publicados sobre o tema; as instituições com presença mais significativa nessa produção científica, sua natureza e as áreas de atuação; a rede de colaboração científica institucional brasileira que conduz pesquisas sobre hanseníase; e os agrupamentos das instituições, de acordo com as relações de coautoria vigentes.

\section{REFERENCIAL TEÓRICO}

\section{Comunicação científica: artigos científicos como fontes de informação}

O conhecimento científico perpassa por etapas para a sua construção: tem início na inquietação do pesquisador, passando pelo estudo do que foi produzido no passado, caminhando para a pesquisa aplicada e a elaboração da escrita, culminando na sua circulação e nas eventuais publicações. Garvey e Griffith (1979) definem esse processo como comunicação científica. Valerio e Pinheiro (2008) complementam esse pensamento ao caracterizá-la como um conjunto de atividades associadas à produção, à disseminação e ao uso da informação e ao apontar que a comunicação científica estabelece o diálogo entre pares. Maia e Caregnato (2005) observam que, para ocorrer a efetivação da comunicação científica, é necessária a conformação de alguns elementos: os produtores ou autores, os canais de divulgação (periódicos, livros etc.), as mensagens transmitidas pelos autores através dos canais e, finalmente, os receptores da informação - os leitores. 
Nesse contexto, aponta-se a relevância do papel dos periódicos científicos, surgidos na metade do século XVII na Inglaterra, para suprir a necessidade de comunicação de uma parcela de pesquisadores pertencentes às sociedades científicas que não podiam estar presentes nas reuniões onde se discutiam pesquisas, mas que desejavam ser informados, da forma mais eficiente possível, das novas descobertas e realizações dos grupos. Assim, a criação e difusão desse tipo de literatura é o marco para a formalização do processo de comunicação científica (MEADOWS, 1999).

Os artigos científicos publicados em periódicos são um dos meios formais da comunicação científica, que possuem por objetivo principal a divulgação de pesquisas, estudos originais e outros tipos de trabalhos intelectuais, sendo atualmente a ferramenta de divulgação mais difundida e utilizada na comunidade acadêmica. De acordo com Cunha (2001), os artigos científicos são uma fonte de informação indispensável de orientação e pesquisa bibliográfica.

Martins e Braile (2009) apontam que os artigos científicos atendem à necessidade de se ampliar a divulgação científica em larga escala, devido à agilidade da publicação, ao formato reduzido e à qualidade atribuída às descobertas publicadas. Assim, o artigo científico se tornou o meio de comunicação mais eficaz para difusão e ampliação do conhecimento em ciência, sendo uma das principais fontes de informação para se entender quais assuntos estão sendo mais estudados nas diversas áreas do conhecimento.

\section{Comunidades discursivas e a colaboração científica por meio da coautoria como análise de domínio}

A compreensão da produção e o uso do conhecimento no meio científico requerem que se observem comportamentos, relacionamentos e a organização entre cientistas, a fim de entender como esses agentes transmitem a informação entre si. Esse fato ocorre pelo fato de a ciência ser uma atividade eminentemente social (VANZ; STUMPF, 2010).

Nascimento e Marteleto (2004) caracterizam esses grupos sociais como comunidades discursivas, pois estão sincronizados em pensamento, linguagem e conhecimento e atrelados por dimensões culturais, sociais e históricas. A partir dos estudos de Swales (1990), esses autores atribuem às comunidades discursivas seis características para a sua identificação: metas comuns, mecanismos participativos, troca de informações, estilos específicos, terminologia especializada e alto nível de especialização. Assim, os sujeitos presentes nas comunidades discursivas formam os colégios invisíveis, termo amplamente utilizado na literatura acadêmica, para determinar grupos que partilham mais do que uma afiliação, idioma ou nacionalidade partilham interesses e temas comuns na elaboração e na construção do conhecimento científico.

Hjørland e Albrechtsen (1995) propõem o uso da análise de domínio como método de estudo na ciência da informação (CI), afirmando que a melhor maneira de se entender a informação, nesse campo, seria estudando os domínios do conhecimento e as suas comunidades discursivas, com uma abordagem focada mais no contexto do que no indivíduo. Smiraglia (2011) define a análise de domínio como o estudo dos aspectos teóricos de uma área do conhecimento, representado pela literatura e comunicação científica formal.

Nesse contexto, destaca-se que os estudos de análise de domínio constituem "marcante abordagem para caracterização e avaliação da ciência, na medida em que permitem identificar as condições pelas quais o conhecimento científico se constrói e se socializa" (GUIMARÃES, 2014, p. 15).

Assim, para a compreensão de um domínio Hjørland (2002) propõe 11 abordagens que, aplicadas em par ou em maior número, possibilitam o entendimento de uma comunidade discursiva e do seu papel na ciência. Entre as abordagens propostas estão os estudos bibliométricos, que para Hjørland e Albrechtsen (1995), quando aplicados no contexto da análise de domínio, além de explicitarem as relações estabelecidas entre disciplinas, contribuem para evidenciar os padrões sociais na comunicação científica. 
Segundo Oliveira e Grácio (2011, p. 19), a bibliometria e os estudos bibliométricos são:

\begin{abstract}
Conjunto de estudos relacionados à avaliação da informação produzida, mais especialmente científica, em diferentes suportes, baseados em recursos quantitativos como ferramentas de análise. Fundamentados na sociologia da ciência, na ciência da informação, matemática, estatística e computação, são estudos de natureza teórico-conceitual, quando contribuem para o avanço do conhecimento da própria temática, propondo novos conceitos e indicadores, bem como reflexões e análises relativas à área. São, também, de natureza metodológica, quando se propõem a dar sustentação aos trabalhos de caráter teórico da área onde estão aplicados.
\end{abstract}

Alves, B. H. (2018) aponta que no campo da bibliometria os indicadores bibliométricos podem ser entendidos como dados estatísticos, usados como parâmetros para a avaliação dos resultados das atividades científicas. Segundo Narin, Olivastro e Stevens (1994); Callon, Courtial e Penan (1995); e Spinak (1998), os indicadores bibliométricos podem ser agrupados em três categorias: indicadores de produção, indicadores de citação e indicadores de ligação.

Ao revisar a literatura sobre indicadores bibliométricos, Grácio (2020) aponta que eles podem ser agrupados em três tipos: produção (índice de produtividade, índice de eficiência, taxa de crescimento, índice de participação na ciência, entre outros); citação (média de citação, índice h, fator de impacto, entre outros); e ligação (colaboração científica, cocitação, acoplamento bibliográfico, rede de citação, coocorrência de termos, entre outros).

No contexto de estudos de cocitação, Grácio e Oliveira (2014) destacam a relevância dessas análises por contribuírem para a visualização do processo comunicativo das interações ocorridas, explicitando a estrutura subjacente de um domínio científico. Ampliando esse entendimento, considerando que também os estudos de colaboração científica evidenciam as ligações estabelecidas de forma ativa dentro de uma comunidade discursiva, formada pelos diferentes atores envolvidos no trabalho científico de um campo do conhecimento, podemos inferir que o estudo das redes de coautoria configura importante método para a visualização das proximidades teórico-metodológicas que formam a estrutura de um domínio, permitindo caracterizar o padrão de colaboração e interlocução vigente no campo estudado.

Vanz e Stumpf (2010) apontam que a coautoria é uma faceta da colaboração científica, pelo fato de que nem todas as colaborações são formalizadas em artigos publicados, uma vez que também acontecem de maneira informal nos ambientes onde os cientistas circulam e trocam informações, como, por exemplo, os eventos científicos das áreas. Apesar dessa limitação, as autoras apontam que estudos bibliométricos têm utilizado com sucesso a coautoria para investigar a colaboração entre pessoas, instituições e países, pois o método possibilita a verificação de grandes volumes de dados públicos pelos pesquisadores, apresentando resultados significativos (KATZ; MARTIN, 1997).

Glänzel (2003) aponta que, embora em nível intrainstitucional, mediante colaborações, por exemplo, entre grupos de pesquisa, laboratórios ou departamentos de uma mesma instituição, as críticas à adoção da coautoria como medida de colaboração tenham procedência, o mesmo não se aplica às colaborações interinstitucionais, especialmente às colaborações internacionais, visto que essas são muito bem reconhecidas. Segundo o autor, os resultados da pesquisa colaborativa nesse nível são refletidos por coautoria dos estudos publicados, que podem, por sua vez, ser analisados com a ajuda de métodos bibliométricos.

Na concepção clássica, a colaboração científica é caracterizada como um trabalho cooperativo entre dois pesquisadores que compartilham dados, equipamentos e/ou ideias em um projeto, que resulta, em geral, em pesquisas publicadas em artigos científicos (VANZ; STUMPF, 2010).

Balancieri et al. (2005), Leydesdorff e Wagner (2009), Luukkonen et al. (1993) e Sobral et al. (2016) apontam que a necessidade de o pesquisador trabalhar de forma colaborativa vem crescendo constantemente no campo da ciência e que essas relações se dão por diversos motivos, tais como: desejo de aumentar a 
produtividade científica; a visibilidade e o reconhecimento pessoal; aumento da produtividade; obtenção e/ ou ampliação de financiamentos, recursos, equipamentos especiais, materiais; desejo de realizar pesquisa multidisciplinar, entre outros.

Balancieri et al. (2005) e Olmeda Gómez, Perianes-Rodríguez e Ovalle-Perandones (2008) afirmam que trabalhos provenientes da colaboração científica de coautorias múltiplas são fortemente caracterizados pela ampliação do repertório e das ferramentas utilizadas na sua construção, quando comparados a trabalhos desenvolvidos por um único pesquisador, devido ao intercâmbio de informações estabelecido na colaboração entre grupos de pesquisadores de instituições.

\section{Análise de redes sociais (ARS) na produção científica em coautoria}

A construção da relação entre pesquisadores e instituições é conhecida como rede de colaboração científica, ou rede social, e se refere ao conjunto de indivíduos atuantes em uma área e as ligações entre eles. Sobral et al. (2016), Silva et al. (2006) e Reichert et al. (2016) afirmam que as redes sociais são constituídas por um grupo de pessoas, instituições ou relacionamentos conectados por um conjunto de relações sociais que tenha um objetivo em comum, como trabalhar em uma mesma instituição ou estudar assuntos correlacionados. Oliveira e Grácio (2008, p. 39) definem que a função da análise de uma rede social é "modelar as conexões entre os atores, a fim de retratar, descrever e representar a estrutura de um grupo, quer seja composto por países, instituições ou pessoas”.

A representação gráfica da análise de redes sociais é desenhada por uma estrutura de nós, ou vértices, que pode ser representada pelos autores, pelas instituições, pelos países ou grupos de pesquisa, que são os atores dessa rede, conectados por um conjunto de linhas que correspondem aos laços entre esses atores, e que indicam a ocorrência da colaboração científica (SILVA et al., 2006). Tomaél (2005, p. 94) define:

Uma rede social é uma representação formal de atores e suas relações. Delinear a estrutura social por meio de uma rede possibilita a sua análise mediante as matrizes ou a imagem gráfica. No diagrama da rede social, atores são representados por nós, e suas relações, por traços que as demonstram.

Tomaél (2005) identificou na literatura os tipos de grupos que podem ser representados e analisados nas representações gráficas das redes sociais:

- Díade: interação entre dois atores.

- Cliques: grupos de atores com relações estreitas entre si.

- Círculo social: grupo no qual cada ator está ligado direta e fortemente à maioria.

- Cluster: conjunto de relações similares, formando uma área de alta densidade.

A análise de redes sociais é uma abordagem interdisciplinar, oriunda da sociologia, da psicologia social e da antropologia (FREEMAN, 1996), e tem sido aplicada em estudos métricos nas mais diversas áreas do conhecimento.

\section{METODOLOGIA}

Trata-se de um estudo exploratório e qualiquantitativo, com elementos de estudos métricos, tendo adotado como instrumento para coleta de dados a base de dados Web of Science, e para análise, o software VOSviewer.

A escolha da base de dados Web of Science se deu pela sua ampla indexação de documentos da área da saúde e pelo seu prestígio no meio científico, como explicitado por Sobral, Miranda e Silva (2018), quando 
afirmam que parte significativa da literatura em DTN se encontra representada na Web of Science. A escolha do software VOSviewer para a análise dos dados se deu pelo fato de essa ferramenta possuir uma interface amigável, além de processar os dados coletados de forma automática e permitir a criação, visualização e exploração de mapas das redes.

O período analisado possibilita dar continuidade (temporal) aos resultados observados nos estudos mencionados, permitindo verificar se as tendências observadas em períodos anteriores se mantiveram ou se alteraram dada a natureza dinâmica e sempre evolutiva da ciência.

A coleta sistematizada de dados ocorreu no dia 17/02/2021 na base de dados Web of Science utilizando os termos 'leprosy' ou 'hansen disease' nos subcampos 'Título', 'Resumo' e 'Palavras-chave', tendo encontrado 14.646 registros. A inserção de termos sinônimos ou no plural referentes à hanseníase não apresentou diferença no resultado de busca. Em seguida, filtraram-se os resultados, limitando-os por ano de publicação, para o período compreendido entre os anos 2016-2020, resultando em 2.559 registros. Na sequência, filtrou-se o conjunto de publicações, limitando o tipo de documento para artigo científico, cujo refinamento resultou em 1.814 artigos. Para esse conjunto de artigos, aplicou-se um último filtro referente ao país de afiliação, restringindo-se àqueles com pelo menos um dos autores vinculados a instituição do Brasil, o que resultou em 498 artigos. Assim, o universo de pesquisa analisado corresponde a 27,5\% dos artigos publicados no período analisado (2016 a 2020).

Ainda no ambiente da base de dados, foi utilizada a ferramenta análise dos resultados para a observação de aspectos relacionados à produção científica selecionada, como instituições de afiliação, agências financiadoras e maiores produções.

Como critério para compor o conjunto de instituições mais produtivas em pesquisas colaborativas, estabeleceu-se a publicação, em média, de pelo menos um artigo em colaboração por ano, o que corresponde àquelas instituições que publicaram pelo menos 5 artigos no período de 2016 a 2020.

Os dados coletados foram exportados para uma planilha de cálculos, onde foram tratados para possibilitar a análise dos indicadores de produção (total de artigos publicados) e de ligação (tipo de coautoria institucional).

Para padronização dos nomes institucionais, foi elaborado um tesauro que permitiu que os termos duplicados ou grafados incorretamente fossem substituídos por termos controlados. Em seguida, os dados foram inseridos e processados no software VOSviewer, a fim de se obter a representação visual das redes colaborativas de pesquisa envolvendo as instituições mais produtivas no período.

\section{RESULTADOS E DISCUSSÃO}

No período de 5 anos (2016 a 2020), foram publicados 498 artigos científicos com a temática hanseníase na base de dados Web of Science envolvendo instituições de pesquisa brasileiras, distribuídos de forma razoavelmente equilibrada entre os anos analisados, uma vez que foram: 84 artigos em 2016; 106 artigos em 2017; 108 em 2018; 94 em 2019; e 106 artigos em 2020.

Do total de artigos coletados, 452 deles apresentaram coautoria institucional, representando $91 \%$ do total da produção científica dessa área.

\footnotetext{
1 Expressão de busca: TI = ('leprosy' OR 'hansen disease') OR AB = ('leprosy' OR 'hansen disease') OR AK = ('leprosy' OR 'hansen disease') and 2020 or 2019 or 2018 or 2017 or 2016 (Publication years) and Articles (Document types) and BRAZIL (Countries/ regions).
} 


\section{Tabela 1 - Quantidade de artigos publicados e proporção por tipo de coautoria no período de 2016 a 2020}

\begin{tabular}{lcc|} 
Tipo de coautoria & $\begin{array}{c}\mathbf{N}^{\mathbf{0}} \text { de } \\
\text { artigos }\end{array}$ & $\begin{array}{c}\text { Proporção na } \\
\text { produção (\%) }\end{array}$ \\
\hline Autoria única & 46 & 9 \\
\hline Dupla & 103 & 21 \\
\hline Tripla & 93 & 19 \\
\hline Quádrupla ou + & 256 & 51 \\
\hline TOTAL & $\mathbf{4 9 8}$ & $\mathbf{1 0 0}$ \\
\hline
\end{tabular}

Fonte: elaboração dos autores.

Conforme a Tabela 1, a maioria dos artigos (70\%) foi resultante de pesquisas colaborativas envolvendo pelo menos três pesquisadores, em especial com pelo menos quatro autores. Esse resultado sugere que a colaboração não está no âmbito das relações de orientação acadêmica, as quais estão contempladas dentro das relações de coautoria dupla (21\%), mas de parcerias resultantes de efetivo compartilhamento de objetivos e trabalho de equipe de pesquisadores, seja ele intrainstitucional, interinstitucional ou internacional. Por outro lado, pesquisas brasileiras sobre hanseníase desenvolvidas por cientistas brasileiros de forma isolada (individualmente) são escassas, correspondendo a menos de 10\% da ciência gerada. Os dados confirmam o crescimento e a dominância desse tipo de prática na área da saúde, conforme abordado por Viacava (2010), quando apontou que até o ano 2000 cerca de $60 \%$ dos artigos publicados na área da saúde eram de autoria única e, após o ano 2006, mais de 80\% dos estudos já contavam com a colaboração científica.

Esse movimento na busca por colaboração na pesquisa em saúde no Brasil vai ao encontro da proposta da WHO, que define que para um mundo rumo a zero hanseníase as parcerias entre pessoas, instituições e países são fundamentais (WHO, 2020). Em consonância, o grupo internacional de pesquisa em hanseníase intitulado Global Partnership for Zero Leprosy (GPZL) publicou em 2019 o documento 'GPZL Reports on Research Priorities', onde foi desenvolvido um conjunto consensual de prioridades de pesquisa global, sendo o Brasil membro do grupo e representado por diversas instituições e pesquisadores brasileiros (GLOBAL PARTNERSHIP FOR ZERO LEPROSY, 2019). Destaca-se, nesse cenário, a observação da WHO (2020) quanto à crucial contribuição dos conhecimentos que precisam ser gerados para a meta de zero hanseníase, em que são essenciais o interesse contínuo e o investimento em pesquisa.

Nesse sentido, podemos tomar a coautoria como um mecanismo de representação dessas parcerias propostas pela WHO, o que possibilita a mensuração da colaboração científica entre as instituições. Balancieri et al. (2005) afirmam que uma das vantagens presentes na formação de coautorias é a ampliação do repertório de abordagens e ferramentas, possibilitando ao pesquisador o intercâmbio de informações e o compartilhamento de recursos, itens considerados indispensáveis para a construção de pesquisas sólidas. A tendência observada nesta pesquisa vai também ao encontro do apontamento de Sobral (2019) ao afirmar que, no campo das DTN no Brasil, a coautoria é essencial para a sobrevivência acadêmica dos pesquisadores, uma vez que as imposições de pesquisa demandam ações plurais, sem as quais o avanço científico seria profundamente prejudicado.

Seguindo na análise dos dados, a Tabela 2 apresenta as 52 instituições com presença mais significativa nos artigos analisados, por terem publicado pelo menos 5 artigos no período, o equivalente a uma média de um artigo ao ano no período estabelecido. 
Tabela 2 - Instituições mais produtivas no período de 2016 a 2020, considerando artigos científicos publicados em coautoria institucional

(continua)

\begin{tabular}{|c|c|c|c|c|c|}
\hline & Instituição de pesquisa & $\begin{array}{c}\text { Artigos } \\
\text { publicados }\end{array}$ & Natureza & Área de atuação & País \\
\hline 1 & Fundação Oswaldo Cruz & 71 & Pública & Instituto de pesquisa & Brasil \\
\hline 2 & Universidade de São Paulo & 55 & Pública & Universidade & Brasil \\
\hline 3 & Instituto Lauro de Souza Lima & 53 & Pública & Instituto de pesquisa & Brasil \\
\hline 4 & Universidade Federal do Ceará & 43 & Pública & Universidade & Brasil \\
\hline 5 & Fiocruz Mato Grosso do Sul & 36 & Pública & Instituto de pesquisa & Brasil \\
\hline 6 & Universidade Federal de Minas Gerais & 32 & Pública & Universidade & Brasil \\
\hline 7 & Universidade Federal do Pará & 32 & Pública & Universidade & Brasil \\
\hline 8 & Universidade do Estado do Pará & 27 & Pública & Universidade & Brasil \\
\hline 9 & Universidade Federal da Bahia & 25 & Pública & Universidade & Brasil \\
\hline 10 & Universidade de Brasília & 24 & Pública & Universidade & Brasil \\
\hline 11 & Universidade Federal do Rio de Janeiro & 23 & Pública & Universidade & Brasil \\
\hline 12 & Universidade Federal de Goiás & 22 & Pública & Universidade & Brasil \\
\hline 13 & Universidade Federal de Alagoas & 20 & Pública & Universidade & Brasil \\
\hline 14 & Universidade Federal Fluminense & 18 & Pública & Universidade & Brasil \\
\hline 15 & Colorado State University & 17 & Privada & Universidade & EUA \\
\hline 16 & Universidade Federal de Uberlândia & 17 & Pública & Universidade & Brasil \\
\hline 17 & University of California & 17 & Privada & Universidade & EUA \\
\hline 18 & Universidade do Estado do Rio de Janeiro & 15 & Pública & Universidade & Brasil \\
\hline 19 & Universidade Federal do Mato Grosso & 15 & Pública & Universidade & Brasil \\
\hline 20 & $\begin{array}{l}\text { London School of Hygiene \& Tropical } \\
\text { Medicine }\end{array}$ & 13 & Pública & Universidade & $\begin{array}{l}\text { Reino } \\
\text { Unido }\end{array}$ \\
\hline 21 & Universidade Federal de Sergipe & 12 & Pública & Universidade & Brasil \\
\hline 22 & Universidade Federal do Maranhão & 11 & Pública & Universidade & Brasil \\
\hline 23 & Infectious Disease Research Institute & 10 & Privada & Instituto de pesquisa & EUA \\
\hline 24 & Universidade do Estado de Mato Grosso & 10 & Pública & Universidade & Brasil \\
\hline 25 & Leiden University & 9 & Pública & Universidade & Holanda \\
\hline 26 & Swiss Tropical and Public Health Institute & 9 & Pública & Instituto de pesquisa & Suíça \\
\hline 27 & Universidade Federal do Espírito Santo & 9 & Pública & Universidade & Brasil \\
\hline 28 & $\begin{array}{l}\text { Universidade Federal do Rio Grande do } \\
\text { Norte }\end{array}$ & 9 & Pública & Universidade & Brasil \\
\hline 29 & Universidade Federal da Paraíba & 8 & Pública & Universidade & Brasil \\
\hline 30 & Universidade Federal do Piauí & 8 & Pública & Universidade & Brasil \\
\hline 31 & $\begin{array}{l}\text { Centro de Referência Nacional em } \\
\text { Dermatologia Sanitária Dona Libânia }\end{array}$ & 8 & Pública & Instituto de pesquisa & Brasil \\
\hline 32 & Pontifícia Universidade Católica do Paraná & 8 & Privada & Universidade & Brasil \\
\hline 33 & Universidade Federal de Juiz de Fora & 8 & Pública & Universidade & Brasil \\
\hline 34 & Anandaban Hospital Patan Clinic & 7 & Privada & Hospital & Nepal \\
\hline 35 & Universidade Estadual de Campinas & 7 & Pública & Universidade & Brasil \\
\hline 36 & Universidade Estadual Paulista & 7 & Pública & Universidade & Brasil \\
\hline 37 & Universidade Federal de São Paulo & 7 & Pública & Universidade & Brasil \\
\hline
\end{tabular}


(conclusão)

\begin{tabular}{|llcccc} 
Instituição de pesquisa & $\begin{array}{c}\text { Artigos } \\
\text { publicados }\end{array}$ & Natureza & Área de atuação & País \\
\hline 38 & Universidade Sagrado Coração & 6 & Privada & Universidade & Brasil \\
\hline 39 & American Leprosy Missions & Privada & $\begin{array}{c}\text { Org. não } \\
\text { governamental }\end{array}$ & EUA \\
\hline 40 & École Polytechnique Fédérale de Lausanne & 6 & Pública & Universidade & Suíça \\
\hline 41 & Netherlands Leprosy Relief & 6 & Privada & Org. não & Hovernamental \\
\hline 42 & Universidade Estadual de Londrina & 6 & Pública & Universidade & Brasil \\
\hline 43 & University of Basel & 6 & Pública & Universidade & Suíça \\
\hline 44 & $\begin{array}{l}\text { Instituto Evandro Chagas } \\
\text { Instituto Nacional de Ciência e Tecnologia }\end{array}$ & 5 & Pública & Instituto de pesquisa & Brasil \\
\hline 46 & Ministério da Saúde & Pública & Instituto de pesquisa & Brasil \\
\hline 47 & Universidade do Estado do Amazonas & 5 & Pública & Entidade do governo & Brasil \\
\hline 48 & University of Southern California & 5 & Pública & Universidade & Brasil \\
\hline 49 & Universidade Estadual de Maringá & 5 & Privada & Universidade & EUA \\
\hline 50 & Universidade Federal do Triângulo Mineiro & 5 & Pública & Universidade & Brasil \\
\hline 51 & $\begin{array}{l}\text { Universidade Federal Rural do Rio de } \\
\text { Janeiro }\end{array}$ & 5 & Pública & Universidade & Brasil \\
\hline 50 & 5 & Privada & Universidade & Austrália \\
\hline
\end{tabular}

Fonte: elaboração dos autores.

A rede de pesquisa brasileira em hanseníase, representada na Tabela 2, faz um contraponto com os dados de Jardim et al. (2020) que, ao analisar as pesquisas individuais sobre o tema, identificou instituições distintas como aquelas mais produtivas, com exceção da Fundação Oswaldo Cruz, que se destaca tanto no âmbito da atuação individual quanto no âmbito das redes colaborativas de pesquisa na área. Também Grácio et al. (2020) destacam o reconhecimento da liderança dessa instituição de pesquisa, ao observar que artigos científicos em coautoria nacional, nos quais a Fundação Oswaldo Cruz (Fiocruz) ocupa a posição de liderança, tiveram um impacto maior (avaliado pelas citações recebidas) do que aqueles em que não ocupa posição de liderança.

As instituições do tipo 'pública' (42, equivalente a 81\%) são predominantes em relação às instituições do tipo 'privada' (10), indicando que no Brasil as pesquisas sobre a temática hanseníase ocorrem principalmente com recursos públicos governamentais ou de agências de fomento de pesquisa. Analisando os resultados na base de dados Web of Science, foi possível observar que, do total de artigos selecionados, 184 (37\%) foram explicitamente declarados como financiados por uma ou mais agências de fomento brasileiras, sendo que as 5 agências que mais investiram nesses estudos são brasileiras ( 2 federais e 3 estaduais), a saber: Conselho Nacional de Desenvolvimento Científico e Tecnológico (CNPq), Coordenação de Aperfeiçoamento de Pessoal de Nível Superior (Capes), Fundação de Amparo à Pesquisa do Estado de Minas Gerais (FAPEMIG), Fundação Carlos Chagas Filho de Amparo à Pesquisa do Estado do Rio de Janeiro (FAPERJ), Fundação de Amparo à Pesquisa do Estado de São Paulo (FAPESP).

Por um lado, esse resultado configura uma característica positiva ao sinalizar que a comunidade científica está atenta à necessidade de avanços na ciência a fim de erradicar a doença no Brasil, ao dedicar subsídios específicos para os estudos do tema; por outro, acena como alerta para o fato de a doença ainda ser uma realidade no cenário brasileiro na segunda década do século XXI - o que demanda esforços e investimentos 
públicos. Ademais, considerando que a Capes é o principal órgão público brasileiro responsável pelo acompanhamento da expansão e consolidação da pós-graduação (mestrado e doutorado) em todos os estados do Brasil (GRÁCIO; OLIVEIRA; WOLFRAM, 2019), esse resultado evidencia que o tema ainda é, contemporaneamente, foco de pesquisa da formação de novos pesquisadores brasileiros.

Quanto à área de atuação, as instituições estão distribuídas em Universidades (40); Institutos de pesquisa (8); Organizações não governamentais (2); Hospital (1); e Entidade do governo (1). As universidades podem ser consideradas um subconjunto significativo, na medida em que representam $77 \%$ do total das instituições estudadas. No entanto, apesar de se apresentarem em maior número, suas contribuições são, em geral, pulverizadas, enquanto as produções científicas dos institutos de pesquisa tendem a se concentrar em poucas instituições.

Em relação ao país de origem das instituições selecionadas para análise, a prevalência é de instituições do Brasil (39) - fato esperado, considerando-se que o critério de busca foi ter entre os responsáveis pela publicação pelo menos uma autoria brasileira, seguido de EUA (5), Suíça (3), Holanda (2), e Nepal, Austrália e Reino Unido, cada um com uma ocorrência no conjunto de artigos analisados. Assim, entre os principais parceiros científicos internacionais do Brasil no tema, estão universidades privadas dos Estados Unidos e públicas do Reino Unido e da Suíça, organizações não governamentais dos Estados Unidos e da Holanda, e institutos de pesquisa dos Estados Unidos (privado) e da Suíça (público).

Sobre a distribuição geográfica em território brasileiro, as 5 regiões do país estão representadas, sendo: Sudeste (16), Nordeste (11), Centro-Oeste (5), Norte (3) e Sul (3). Hoppen et al. (2017) realizam uma extensa análise sobre a distribuição geográfica da atividade de pesquisa no Brasil na área de ciências biomédicas, trazendo luz ao fato de a concentração estar localizada na região Sudeste pelo motivo histórico de os primeiros institutos de pesquisa brasileiros terem surgido nessa área no fim do século XIX e início do século XX. Os autores apontam ainda que, apesar da desigualdade entre as regiões, houve crescimento expressivo das atividades de pesquisa no país nas últimas décadas em decorrência dos investimentos em políticas públicas e na implantação de universidades em áreas remotas do país, promovidos pelo Governo Federal no início do século XXI.

Ao analisar o volume da produção científica gerada pelas 52 instituições, fica evidente que poucas instituições publicaram muito no período estudado e que muitas publicaram pouco. Tal fenômeno é explicado na literatura pela Lei de Lotka (ARAÚJO, 2006), que afirma que uma larga proporção da literatura científica é produzida por um pequeno número de autores, nesse caso de instituições.

A Figura 1 apresenta a rede de coautoria institucional responsável pelos artigos decorrentes de pesquisas colaborativas em hanseníase, em que pelo menos um dos autores é vinculado à instituição brasileira. Nela, observa-se a configuração de nove conjuntos, ou clusters, de instituições. Na sequência, apresenta-se o Quadro 1 com as 52 instituições distribuídas nos nove clusters identificados na rede de coautoria. 


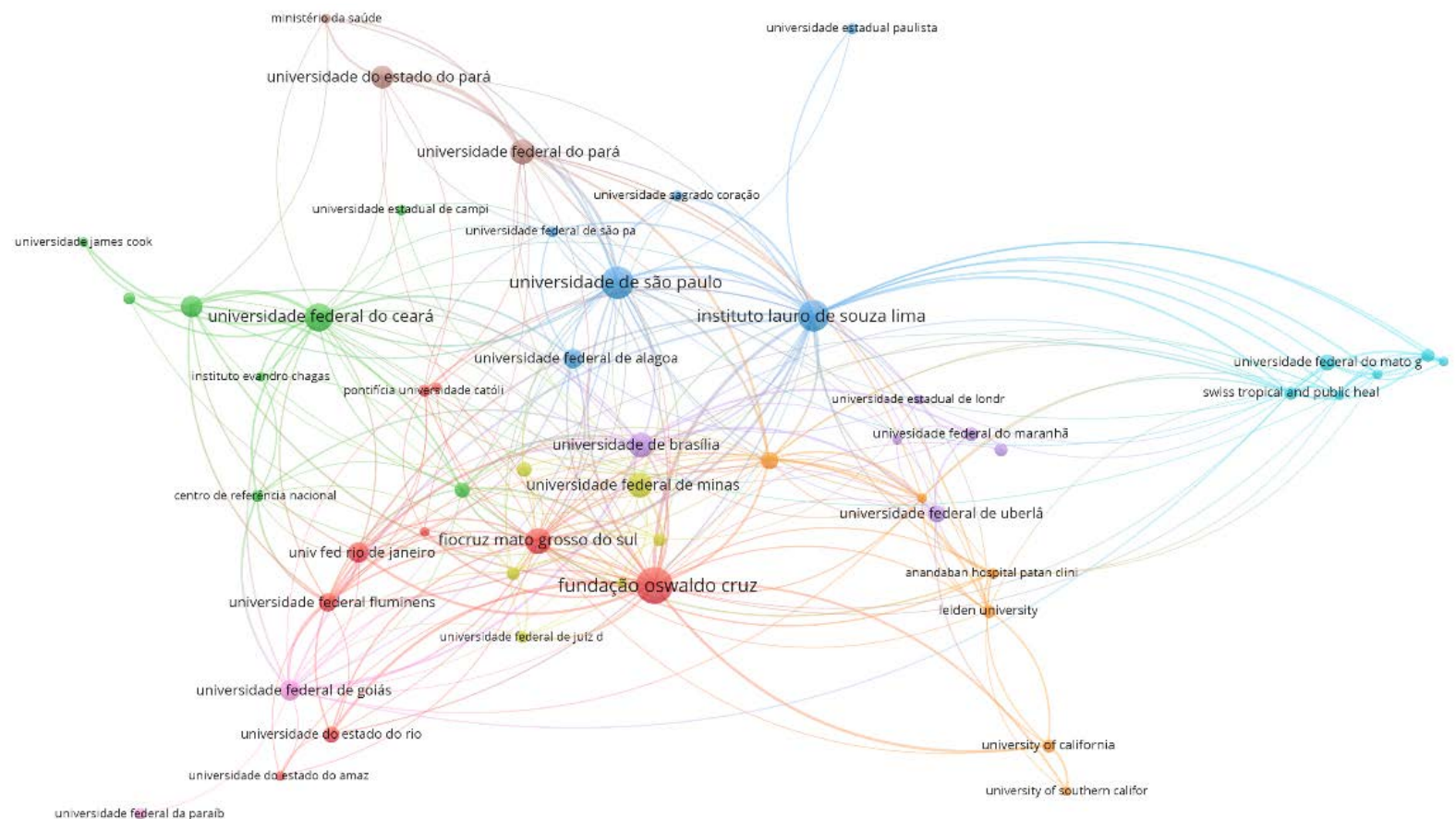

Figura 1 - Rede de coautoria realizada pelas instituições

Fonte: elaboração dos autores com auxílio do VOSviewer.

Destacado em vermelho, o maior cluster é formado por nove instituições, majoritariamente universidades públicas distribuídas por diversos estados brasileiros. É liderado pela Fiocruz, representada pelo maior círculo do mapa, denotando sua centralidade na rede de colaborações. O segundo maior cluster (em verde) abrange oito instituições, em sua maioria também universidades, e está centrado na Universidade Federal do Ceará.

\section{Quadro 1 - Instituições de pesquisa divididas em clusters}

(continua)

\begin{tabular}{|l|l|}
\hline Gluster $\mathbf{1}$ (9 itens) - Vermelho & Gluster 5 (6 itens) - Roxo \\
\hline Fiocruz Mato Grosso do Sul & Universidade de Brasília \\
\hline Fundação Oswaldo Cruz & Universidade Estadual de Londrina \\
\hline Pontifícia Universidade Católica do Paraná & Universidade Federal de Uberlândia \\
\hline Universidade Federal do Rio de Janeiro & Universidade Federal do Espírito Santo \\
\hline Universidade do Estado do Amazonas & Universidade Federal do Triângulo Mineiro \\
\hline Universidade do Estado do Rio de Janeiro & Universidade Federal do Maranhão \\
\hline Universidade Estadual de Maringá & \\
\hline Universidade Federal Fluminense & \\
\hline Universidade Federal Rural do Rio de Janeiro & \\
\hline Cluster $\mathbf{2}$ (8 itens) - Verde & Cluster 6 (6 itens) - Turquesa \\
\hline $\begin{array}{l}\text { Centro de Referência Nacional em Dermatologia Sanitária Dona } \\
\text { Libânia }\end{array}$ & American Leprosy Missions \\
\hline Instituto Evandro Chagas & Netherlands Leprosy Relief \\
\hline London School of Hygiene \& Tropical Medicine & Swiss Tropical and Public Health Institute \\
\hline Universidade Estadual de Campinas & Universidade do Estado de Mato Grosso \\
\hline Universidade Federal da Bahia & Universidade Federal do Mato Grosso \\
\hline Universidade Federal do Piauí & University of Basel \\
\hline Universidade Federal do Ceará & \\
\hline James Cook University & \\
\hline
\end{tabular}




\begin{tabular}{|l|l|}
\hline Cluster $\mathbf{3}$ (6 itens) - Azul & Cluster 7 (6 itens) - Laranja \\
\hline Instituto Lauro de Souza Lima & Anandaban Hospital Patan Clinic \\
\hline Universidade de São Paulo & Colorado State University \\
\hline Universidade Estadual Paulista & Leiden University \\
\hline Universidade Federal de Alagoas & University of California \\
\hline Universidade Federal de São Paulo & University of Southern California \\
\hline Universidade Sagrado Coração & École Polytechnique Fédérale de Lausanne \\
\hline & \\
\hline Cluster $\mathbf{4}$ (6 itens) - Amarelo & Cluster 8 (3 itens) - Marrom \\
\hline Infectious Disease Research Institute & Ministério da Saúde \\
\hline Instituto Nacional de Ciência e Tecnologia de Doenças Tropicais & Universidade do Estado do Pará \\
\hline Universidade Federal de Juiz de Fora & Universidade Federal do Pará \\
\hline Universidade Federal de Minas Gerais & \\
\hline Universidade Federal de Sergipe & \\
\hline Universidade Federal do Rio Grande do Norte & \\
\hline & Cluster 9 (2 itens) - Rosa \\
\hline & Universidade Federal da Paraíba \\
\hline & Universidade Federal de Goiás \\
\hline
\end{tabular}

Fonte: elaboração dos autores com auxílio do VOSviewer.

No cluster 3 (em azul), estão representadas seis instituições, cinco delas universidades, e a sua centralidade é compartilhada entre o Instituto Lauro de Souza Lima e a Universidade de São Paulo, ambos com círculos (representativos das quantidades de publicações) e laços colaborativos de proporções semelhantes. Na sequência, ainda com seis instituições, estão os clusters amarelo, roxo, turquesa e laranja, liderados respectivamente pela Universidade Federal de Minas Gerais, pela Universidade de Brasília, pelo Swiss Tropical and Public Health Institute e pela Colorado State University.

De menor proporção, ainda estão representados os clusters marrom (3 instituições) e rosa (2 instituições), liderados pela Universidade Federal do Pará e pela Universidade Federal da Paraíba, respectivamente.

Sobre a centralidade dos clusters, o que indica sua influência e seu alto nível de colaboração científica, é possível observar que há predomínio dos conjuntos vermelho (cluster 1) e azul (cluster 3), estando os demais conjuntos em níveis mais periféricos da rede.

Destaca-se, ainda, o fato de os clusters 1, 3, 5, 8 e 9 serem constituídos unicamente por instituições brasileiras. Por outro lado, o cluster 7 abrange somente instituições estrangeiras, com significativa colaboração com instituições de outros clusters, especialmente os clusters vermelho (1), turquesa (6) e marrom (8). Os clusters 2, 4 e 6 são compostos por instituições brasileiras e estrangeiras.

\section{CONSIDERAÇÕES FINAIS}

Dentro dos limites propostos pela pesquisa os objetivos foram cumpridos, tendo sido possível identificar as relações de coautoria institucionais estabelecidas entre as organizações mais produtivas e representadas na base de dados Web of Science que publicaram artigos científicos com a temática hanseníase no período de 2016 a 2020.

As universidades, apesar de liderarem em quantidade absoluta de instituições, não lideram a centralidade da rede, que é representada principalmente por institutos de pesquisa, cujas publicações estão concentradas em poucas instituições, enquanto as das universidades estão pulverizadas em muitas unidades. Sobre essa 
perspectiva, existe a probabilidade de as universidades serem organismos que contribuem para as pesquisas lideradas pelos institutos de pesquisa, devido à posição periférica que ocupam no mapa, mas a verificação dessa suposição somente seria válida ao se analisar a posição que ambas ocupam nas ordens de autoria dos artigos científicos quem compõem a amostra.

No decorrer da coleta de dados houve extensa dificuldade em agrupar os documentos por instituições, devido à falta de padronização de nomes institucionais. Por esse motivo não foi possível desconsiderar as coautorias com pesquisadores da mesma instituição, mas de departamentos diferentes, pois os sistemas automatizados as entendem como afiliações diferentes. Esse entrave não altera o número total da produção científica de cada instituição, nem a sua posição na rede de colaboração, mas pode mascarar os valores reais dos tipos de coautorias múltiplas localizadas.

A leve prevalência de colaboração com países norte-americanos foi um fato surpreendente revelado pelos dados. Havia a expectativa de maior colaboração com países com maior taxa de endemicidade de hanseníase. Esse fato pode ter se dado em virtude de o local da coleta de dados ser uma base de origem estadunidense que publica, predominantemente, em língua inglesa.

Considera-se que, para validação ou refutação desse evento, torna-se necessário expandir o ambiente da coleta de dados, alcançando bases de dados diversas e com maior abrangência geográfica. Apesar dos limites impostos pela escolha da base de dados, ressalta-se a abrangência e a importância da Web of Science no cenário científico mundial. Sendo assim, as análises efetuadas nessa pesquisa não esgotam as possibilidades de investigação sobre o tema, mas abrem precedentes para a aplicação da metodologia em outros repositórios de informação.

Por fim, fica claro que as pesquisas conduzidas em coautoria institucional podem ser uma das facetas da parceria entre países e instituições, ponto fortemente incentivado pela WHO na proposta de uma estratégia global rumo a zero hanseníase, visto que em seu entendimento, a WHO propõe que os países que já alcançaram a meta de eliminação da doença encorajem e alavanquem esforços para que os países endêmicos acelerem o combate à hanseníase.

Os resultados obtidos nesta pesquisa levantam diversas oportunidades para pesquisas futuras, algumas das quais são destacadas a seguir.

Nas últimas décadas, vários estudiosos têm se dedicado a avaliar a contribuição dos autores de acordo com sua posição (primeiro, intermediário, último autor, autor correspondente) na linha de autoria dos artigos em colaboração científica, entre eles Yang, Wolfram e Wang (2017); Corrêa et al. (2017); Duffy (2017); Larivière et al. (2016); Youtie e Borzeman (2014). Observam que, em geral, a posição de primeiro autor é ocupada pelo autor principal da pesquisa e a posição de último autor ocupada pelo orientador/ supervisor do projeto, assim como o autor correspondente é identificado também como um papel de liderança na equipe de pesquisa. Nesse sentido, sugere-se que estudos subsequentes analisem a posição ocupada na linha de autoria pelos autores vinculados às instituições brasileiras, a fim de se identificar sua liderança nas pesquisas em hanseníase, representada pela posição por eles ocupada - primeiro autor, último autor ou autor correspondente.

Ainda considerando que a literatura científica tem apontado que a colaboração internacional tem um ganho de citação maior do que a nacional ou intrainstitucional (CHINCHILLA-RODRÍGUEZ; SUGIMOTO; LARIVIÈRE, 2019), assim como a influência do primeiro autor ou do autor de correspondência sobre o impacto da publicação (BU et al., 2019), considera-se que estudos futuros possam ser desenvolvidos a fim de analisar a potencial influência da presença internacional nos artigos colaborativos brasileiros sobre o impacto alcançado. Além disso, considera-se que essa abordagem pode contribuir para a compreensão de como a produção científica nacional ou internacional está sendo reconhecida pela comunidade internacional, aproveitando os pontos fortes de especialização dos parceiros. 
Uma questão adicional que surge nesta pesquisa diz respeito ao idioma de publicação. Estudiosos, como Egghe e Rousseau (2000), têm observado que periódicos em outros idiomas alcançam um nível de impacto de citação inferior ao de veículos que publicam em inglês, uma vez que a oportunidade de alcançar um amplo público de leitores, mesmo que o trabalho possa ser de grande interesse, é diminuída pela linguagem da publicação (VAN LEEUWEN et al., 2001). Seguindo essa linha de raciocínio, questiona-se a influência do idioma de publicação no impacto da citação das pesquisas brasileiras em hanseníase: o idioma da publicação brasileira afeta o impacto da citação? Com base em evidências empíricas apresentadas em artigos anteriores (VAN LEEUWEN et al., 2001; LIANG; ROUSSEAU; ZHONG, 2013; LIU et al., 2018), sugerimos que pesquisas futuras avaliem se o fato de artigos brasileiros serem publicados em português afeta negativamente o impacto de citação.

\section{REFERÊNCIAS}

ALVES, Bruno Henrique. Sociologia de Pierre Bourdieu e os pesquisadores bolsistas de produtividade em pesquisa do CNPQ em ciência da informação. 2018. 158 f. Tese (Doutorado em Ciência da Informação) - Faculdade de Filosofia e Ciências, Universidade Estadual Paulista, Marília, 2018.

ALVES, Natália L. Hanseníase: o que está sendo "eliminado"? 2018. 55 f. Dissertação (Mestrado em Ciências Aplicadas a Produtos para Saúde) - Universidade Estadual de Goiás, Anápolis, 2018.

ARAÚJO, Carlos Alberto. Bibliometria: evolução histórica e questões atuais. Em Questão, Porto Alegre, v. 12, n. 1, p. 11-32, 2006. Disponível em: https://seer.ufrgs.br/EmQuestao/article/view/16/5. Acesso em: 04 mar. 2021.

BALANCIERI, Renato et al. A análise de redes de colaboração científica sob as novas tecnologias de informação e comunicação: um estudo na Plataforma Lattes. Ciência da Informação, Brasília, DF, v. 34, n. 1, p. 64-77, 2005. Disponível em: https://www.scielo.br/j/ci/a/C65dbRvBt77DQ3TQfSmDtPx/?lang=pt\&format= pdf. Acesso em: 20 ago. 2021.

BENDER, Max Ernst et al. Using co-authorship networks to map and analyse global Neglected Tropical Disease research with an affiliation to Germany. PLoS Neglected Tropical Disease, São Francisco, v. 9, n. 12, p. e0004182, 2015. DOI: https://dx.doi.org/10.1371\%2Fjournal.pntd.0004182. Disponível em: https:// www.ncbi.nlm.nih.gov/pmc/articles/PMC4703140/. Acesso em: 10 maio 2021.

BRASIL. Ministério da Saúde. Secretaria de Políticas da Saúde. Departamento de Atenção Básica. Guia para o controle da hanseníase. Brasília, DF: Ministério da Saúde, 2002. Disponível em: https://bvsms.saude.gov. br/bvs/publicacoes/guia_de hanseniase.pdf. Acesso em: 29 nov. 2021.

$\mathrm{BU}$, Yi et al. Investigating scientific collaboration through the sequence of authors in the publication bylines and the diversity of collaborators. In: INTERNATIONAL CONFERENCE ON SCIENTOMETRICS AND INFORMETRICS, 17, $2-5$ set. 2019, Roma. Proceedings [...]. Roma: Edizioni Efesto, 2020. v. 2, p. 2300-2305. Disponível em: https://www.issi-society.org/proceedings/issi_2019/ISSI\%202019\%20-\%20 Proceedings\%20VOLUME\%20ll.pdf. Acesso em: 30 nov. 2021.

CALLON, Michel; COURTIAL, Jean Pierre; PENAN, Hervé. Cientometría. Gijón: TREA, 1995.

CASTORINA-SILVA, Rozana. Tratamento da hanseníase. In: LYON, Sandra; GROSSI, Maria Aparecida de Faria. Hanseníase. Rio de Janeiro: MedBook, 2013. p.199-206.

CHINCHILLA-RODRÍGUEZ, Zaida; SUGIMOTO, Cassidy; LARIVIĖRE, Vincent. Follow the leader: on the relationship between leadership and scholarly impact in international collaborations. PLoS One, São Francisco, v. 14, n. 6, p. e0218309, 2019. DOI: https://dx.doi.org/10.1371\%2Fjournal.pone.0218309. Disponível em: https://journals.plos.org/plosone/article?id=10.1371/journal.pone.0218309. Acesso em: 30 nov. 2021.

CORRÊA JR., Edilson A. et al. Patterns of authors contribution in scientific manuscripts. Journal of Informetrics, [s. I.], v. 11, n. 2, p. 498-510, 2017. DOI: https://doi.org/10.1016/j.joi.2017.03.003. Disponível em: https://www.sciencedirect.com/science/article/abs/pii/S1751157716302693. Acesso em: 30 nov. 2021.

CUNHA, Murilo B. da. Para saber mais: fontes de informação em ciência e tecnologia. Brasília, DF: Briquet de Lemos, 2001. 
DUFFY, Meghan A. Last and corresponding authorship practices in ecology. Ecology and Evolution, [s. I.], v. 7, n. 21, p. 8876-8887, 2017. DOI: https://doi.org/10.1002/ece3.3435. Disponível em: https://onlinelibrary. wiley.com/doi/10.1002/ece3.3435. Acesso em: 30 nov. 2021.

EGGHE, Leo; ROUSSEAU, Ronald. Partial orders and measures for language preferences. Journal of the American Society for Information Science, [s. I.], v. 51, n. 12, p. 1123-1130, 2000. Disponível em: https:// ideas.repec.org/a/bla/jamest/v51y2000i12p1123-1130.html. Acesso em: 30 nov. 2021.

FALAGAS, Matthew E.; KARAVASIOU, Antonia I.; BLIZIOTIS, Ioannis A. A bibliometric analysis of global trends of research productivity in tropical medicine. Acta Tropica, Amsterdã, v. 99, n. 2-3, p. 155-159, 2006. Disponível em: https://www.sciencedirect.com/science/article/abs/pii/S0001706X06001550. Acesso em: 10 maio 2021.

FERREIRA, Isaias Nery. A hanseníase no contexto das doenças negligenciadas. In: ALVES, Elioenai Dornelles; FERREIRA, Telma Leonel; FERREIRA, Isaias Nery (org.). Hanseníase: avanços e desafios. Brasília, DF: Universidade de Brasília, 2014. p. 41-44. Disponivel em: http://www.morhan.org.br/views/ upload/hanseniaseavancoes.pdf. Acesso em: 05 ago. 2019.

FONTECHA, Gustavo; SÁNCHEZ, Ana; ORTIZ, Bryan. Publication trends in neglected tropical diseases of Latin America and the Caribbean: a bibliometric analysis. Pathogens, Basel, v. 10, n. 3, p. 356, 2021. DOI: https://dx.doi.org/10.3390\%2Fpathogens10030356. Disponível em: https://www.ncbi.nlm.nih.gov/pmc/ articles/PMC8002643/. Acesso em: 10 maio 2021.

FREEMAN, Linton C. Some antecedents of social network analysis. Connections, Boston, v. 19, n. 1, p. 3942, 1996. Disponivel em: http://citeseerx.ist.psu.edu/viewdoc/download?doi=10.1.1.211.8162\&rep=rep1\&ty pe=pdf. Acesso em: 30 nov. 2021.

GARVEY, William D.; GRIFFITH, Belver C. Scientific communication as a social system. In: GARVEY, William D. Communication: the essence of science. Oxford: Pergamon, 1979. p. 148-164.

GLÄNZEL, Wolfgang. Indicators of scientific collaboration. In: GLÄNZEL, Wolfgang. Bibliometrics as a research field: a course on theory and application of bibliometric indicators. [S. I.: s. n.], 2003. p. 73-80. Disponível em: https://www.cin.ufpe.br/ ajhol/futuro/references/01\%23 Bibliometrics Module KUL BIBLIOMETRICS\%20AS\%20A\%20RESEARCH\%20FIELD.pdf. Acesso em: 9 fev. 2021.

GLOBAL PARTNERSHIP FOR ZERO LEPROSY. GPZL Reports on Research Priorities. Leprosy Review, Colchester, v. 90, n. 3, p. 237-289, 2019. DOI: https://doi.org/10.47276/lr.90.3.237. Disponível em: https:// leprosyreview.org/article/90/3/23-7289. Acesso em: 18 ago. 2021.

GLOVER, Steven W.; BOWEN, Sarah L. Bibliometric analysis of research published in Tropical Medicine and International Health 1996-2003. Tropical Medicine \& International Health, Oxford, v. 9, n. 12, p. 1327-1330, 2004. DOI: https://doi.org/10.1111/j.1365-3156.2004.01331.x. Disponível em: https://onlinelibrary.wiley.com/ doi/10.1111/j.1365-3156.2004.01331.x. Acesso em: 10 maio 2021.

GRÁCIO, Maria Cláudia Cabrini. Análises relacionais de citação para a identificação de domínios científicos: uma aplicação no campo dos Estudos Métricos da Informação no Brasil. Marília: Oficina Universitária; São Paulo: Cultura Acadêmica, 2020. E-book. DOI: https://doi.org/10.36311/2020.978-6586546-12-5. Disponível em: https://ebooks.marilia.unesp.br/index.php/lab_editorial/catalog/book/166. Acesso em: 23 ago. 2021.

GRÁCIO, Maria Cláudia Cabrini et al. Does corresponding authorship influence scientific impact in collaboration: Brazilian institutions as a case of study. Scientometrics, [s. I.], v. 124, p. 1-16, 2020. DOI: http://dx.doi.org/10.1007/s11192-020-03655-7. Disponível em: https://link.springer.com/article/10.1007\%2 Fs11192-020-03655-7. Acesso em: 30 nov. 2021.

GRÁCIO, Maria Cláudia Cabrini; OLIVEIRA, Ely Francina Tannuri de. Estudos de análise de cocitação de autores: uma abordagem teórico-metodológica para a compreensão de um domínio. Tendências da Pesquisa Brasileira em Ciência da Informação, [s. I.], v. 7, n. 1, jan./jun. 2014. Disponível em: https://repositorio.unesp.br/bitstream/handle/11449/114829/ISSN19835116-2014-07-01-01-22a. pdf? sequence=1\&isAllowed=y. Acesso em: 05 mar. 2021.

GRÁCIO, Maria Cláudia Cabrini; OLIVEIRA, Ely Francina Tannuri de; WOLFRAM, Dietmar. Production and impact of Brazilian papers in Library and Information Science journals (1986-2015). Ciência da Informação, Brasília, DF, v. 48, p. 100-115, 2019. Disponível em: http://revista.ibict.br/ciinf/article/view/4411/4291. Acesso em: 23 ago. 2021. 
GUIMARÃES, José Augusto Chaves. Análise de domínio como perspectiva metodológica em organização da informação. Ciência da Informação, Brasília, DF, v. 41, n. 1, p. 13-21, jan./abr., 2014. Disponível em: http:// revista.ibict.br/ciinf/article/view/1415/1593. Acesso em: 05 mar. 2021.

HJØRLAND, Birger. Domain analysis in Information Science: eleven approaches traditional as well as innovative. Journal of Documentation, Londres, v. 58, n. 4, p. 422-462, 2002. DOI: http://dx.doi. org/10.1108/00220410210431136. Disponível em: https://www.emerald.com/insight/content/ doi/10.1108/00220410210431136/full/html. Acesso em: 29 nov. 2021.

HJØRLAND, Birger; ALBRECHTSEN, Hanne. Toward a new horizon in information science: domain-analysis. Journal of the American Society for Information Science, Washington, DC, v. 46, n. 6, p. 400-425, jul. 1995. DOI: https://doi.org/10.1002/(SICI)1097-4571(199507)46:6\%3C400::AID-ASI2\%3E3.0.CO;2-Y Disponível em: https://asistdl.onlinelibrary.wiley.com/doi/epdf/10.1002/\%28SICl\%2910974571\%28199507\%2946\%3A6\%3C400\%3A\%3AAID-ASI2\%3E3.0.CO\%3B2-Y. Acesso em: 05 mar. 2021.

HOPPEN, Natascha Helena Franz et al. Distribuição geográfica da produção e colaboração científica brasileira nas ciências biomédicas. Em Questão, Porto Alegre, v. 23, Edição Especial 5 EBBC, p. 50-73, 2017. DOI: https://doi.org/10.19132/1808-5245230.50-73. Disponível em: https://seer.ufrgs.br/EmQuestao/article/ view/68049/40075. Acesso em: 08 mar. 2021.

JARDIM, Camila Pereira et al. Análise da produção científica brasileira sobre hanseníase identificada na base de dados Web of Science. Arquivos de Ciências da Saúde da UNIPAR, Umuarama, v. 24, n. 2, p. 105-111, 2020. DOI: https://doi.org/10.25110/arqsaude.v24i2.2020.7709. Disponível em: https://www.revistas.unipar. br/index.php/saude/article/view/7709. Acesso em: 10 maio 2021.

KATZ, J. Sylvan; MARTIN, Ben R. What is research collaboration?. Research Policy, [s. I.], v. 26, n. 1, p. 1-18, 1997. DOI: https://doi.org/10.1016/S0048-7333(96)00917-1. Disponível em: https://www.sciencedirect.com/ science/article/abs/pii/S0048733396009171. Acesso em: 29 nov. 2021.

LARIVIĖRE, Vincent et al. Contributorship and division of labor in knowledge production. Social Studies of Science, [s. I.], v. 46, n. 3, p. 417-435, 2016. DOI: https://doi.org/10.1177\%2F0306312716650046. Disponível em: https://journals.sagepub.com/doi/abs/10.1177/0306312716650046. Acesso em: 30 nov. 2021.

LEYDESDORFF, Loet; WAGNER, Caroline. Macro-level indicators of the relations between research funding and research output. Journal of Informetrics, [s. I.], v. 3, n. 4, p. 353-362, 2009. DOI: https://doi. org/10.1016/j.joi.2009.05.005. Disponível em: https://www.sciencedirect.com/science/article/abs/pii/ S1751157709000418. Acesso em: 29 nov. 2021.

LIANG, Liming; ROUSSEAU, Ronald; ZHONG, Zhen. Non-English journals and papers in physics and chemistry: bias in citations? Scientometrics, [s. I.], v. 95, n. 1, p. 333-350, 2013. DOI: https://doi.org/10.1007/ s11192-012-0828-0. Disponível em: https://link.springer.com/article/10.1007/s11192-012-0828-0. Acesso em: 30 nov. 2021.

LIU, Fang et al. The penalty of containing more non-English articles. Scientometrics, [s. I.], v. 114, n. 1, p. 359366, 2018. DOI: https://doi.org/10.1007/s11192-017-2577-6. Disponível em: https://link.springer.com/article/ 10.1007\%2Fs11192-017-2577-6. Acesso em: 30 nov. 2021.

LUUKKONEN, Terttu et al. The measurement of international scientific collaboration. Scientometrics, [s. I.], v. 28, n. 1, p. 15-36, 1993. DOI: https://doi.org/10.1007/BF02016282. Disponível em: https://link.springer.com/ article/10.1007/BF02016282. Acesso em: 29 nov. 2021.

MAIA, Maria de Fátima S.; CAREGNATO, Sônia Elisa. Co-autoria e colaboração científica entre pesquisadores da saúde: um estudo de caso. In: ENCONTRO NACIONAL DE PESQUISA EM CIÊNCIA DA INFORMAÇÃO, 6. 2005, Florianópolis. Anais [...]. [S. I.: s.n.], 2005.

MARTINS, Cláudia Araújo; BRAILE, Domingo Marcolinoo. Análise cientométrica dos periódicos em ciências da saúde e áreas correlatas disponíveis no Portal de Periódicos da Capes. Perspectivas em Ciência da Informação, Belo Horizonte, v. 14, n. 3, p. 75-93, 2009. Disponível em: https://www.scielo.br/j/pci/a/jpTr7qNB ¡YhYjFvB3jXcmMR/?format=pdf\&lang=pt. Acesso em: 15 fev. 2021.

MEADOWS, Arthur Jack. A comunicação científica. Brasília, DF: Brinquet de Lemos, 1999. 
NARIN, Francis; OLIVASTRO, Dominic; STEVENS, Kimberly A. Bibliometrics: theory, practice and problems. Evaluation Review, [s. I.], v. 18, n. 1, p. 65-76, 1994. DOI: https://psycnet.apa.org/ doi/10.1177/0193841X9401800107. Disponível em: https://psycnet.apa.org/record/1994-39735-001. Acesso em: 29 nov. 2021.

NASCIMENTO, Denise Morado; MARTELETO, Regina Maria. A "informação construída" nos meandros dos conceitos da Teoria Social de Pierre Bordieu. DataGramaZero, João Pessoa, v. 5, n. 5, out. 2004. Disponível em: https://brapci.inf.br/index.php/res/v/5679. Acesso em: 05 mar. 2021.

OLIVEIRA, Ely Francina Tannuri de; GRÁCIO, Maria Cláudia Cabrini. Indicadores bibliométricos em ciência da informação: análise dos pesquisadores mais produtivos no tema estudos métricos na base Scopus. Perspectivas em Ciência da Informação, Belo Horizonte, v. 16, n. 4, p. 16-28, 2011. Disponível em: http:// www.scielo.br/pdf/pci/v16n4/v16n4a03.pdf. Acesso em: 03 mar. 2021.

OLIVEIRA, Ely Francina Tannuri de; GRÁCIO, Maria Cláudia Cabrini. Rede de colaboração científica no tema "estudos métricos": um estudo de coautorias através dos periódicos do Scielo da área de ciência da informação. Brazilian Journal of Information Science, Marília, v. 2, n. 2, p. 35-49, jul./dez. 2008. DOI: https:// doi.org/10.36311/1981-1640.2008.v2n2.04.p35. Disponível em: https://revistas.marilia.unesp.br/index.php/ bjis/article/view/47/45. Acesso em: 02 mar. 2021.

OLMEDA GÓMEZ, Carlos; PERIANES-RODRÍGUEZ, Antonio; OVALLE-PERANDONES, Maria Antonia. Estructura de las redes de colaboración científica entre las universidades españolas. Ibersid: Revista Internacional de Sistemas de Información y Documentación, Zaragoza, v. 2, p. 129-140, 2008. Disponível em: https://ibersid.eu/ojs/index.php/ibersid/article/view/2219/1980. Acesso em: 20 ago. 2021.

REICHERT, Taís Araldi et al. Redes de colaboração científica: um estudo de coautoria através da Análise de Redes Sociais. In: MOSTRA DE INICIAÇÃO CIENTÍFICA, PÓS-GRADUAÇÃO, PESQUISA E EXTENSÃO, 16, 2016, Caxias do Sul. Anais [...]. Caxias do Sul: UCS, 2016. p. 1-14. Disponível em: http://www.ucs.br/etc/ conferencias/index.php/mostraucsppga/xvimostrappga/paper/viewFile/4781/1653. Acesso em: 15 fev. 2021.

SCHOONBAERT, Dirk; DEMEDTS, Veerle. Analysis of the leprosy literature indexed in Medline (1950-2007). Leprosy Review, Colchester, v. 79, n. 4, p. 387-400, 2008. DOI: https://doi.org/10.47276/lr.79.4.387. Disponível em: https://leprosyreview.org/article/79/4/38-7400. Acesso em: 10 maio 2021.

SILVA, Antonio Braz de Oliveira et al. Análise de redes sociais como metodologia de apoio para a discussão da interdisciplinaridade em ciência da informação. Ciência da Informação, Brasília, DF, v. 35, n. 1, p. 72-93, jan.abr. 2006. Disponível em: https://www.scielo.br/j/ci/a/WWpWjQYnfDnb6PH8sQbzVMn/?lang=pt\&format=p df. Acesso em: 15 fev. 2021.

SMIRAGLIA, Richard P. Domain coherence within knowledge organization: people, interacting theoretically, across geopolitical and cultural boundaries. In: MCKENZIE, Pam; JOHNSON, Catherine; STEVENS, Sarah (ed.). Annual Conference of CAIS, Fredericton, 2-4 jun. 2011. Proceedings of the Annual Conference of CAIS = Actes du congrès annuel de l'ACSI, Fredericton, p. 1-6, 2011. DOI: https://doi.org/10.29173/cais601. Disponível em: https://journals.library.ualberta.ca/ojs.cais-acsi.ca/index.php/cais-asci/article/view/601. Acesso em: 29 nov. 2021.

SOBRAL, Natanael Vitor. Pesquisadores em Doenças Tropicais Negligenciadas no Brasil: produção científica e convergências com o Plano Nacional de Saúde (2016 a 2019). 2019. 214 f. Tese (Doutorado em Ciência da Informação) - Instituto de Ciência da Informação, Universidade Federal da Bahia, Salvador, 2019.

SOBRAL, Natanael Vitor et al. Produção científica colaborativa na área da saúde tropical: uma análise da rede de colaboração do Programa de Pós-Graduação em Medicina Tropical da Universidade Federal de Pernambuco. Revista Eletrônica de Comunicação, Informação, Inovação em Saúde, Rio de Janeiro, v. 10, n. 1, p. 1-15, 2016. DOI: https://doi.org/10.29397/reciis.v10i1.1025. Disponível em: https://www.reciis.icict. fiocruz.br/index.php/reciis/article/view/1025/pdf 1025. Acesso em: 15 fev. 2021.

SOBRAL, Natanael Vitor; MIRANDA, Zeny Duarte de; SILVA, Fabio Mascarenhas e. Estratégia para a recuperação de informação científica sobre as Doenças Tropicais Negligenciadas: análise comparativa da Scopus, PubMed e Web of Science. Revista Cubana de Información en Ciencias de la Salud, Havana, v. 29, n. 1, p. 35-53, 2018. Disponível em: http://scielo.sld.cu/pdf/ics/v29n1/a6 1179.pdf. Acesso em: 28 ago. 2021.

SPINAK, Ernesto. Indicadores cienciométricos. Ciência da Informação, Brasília, DF, v. 27, n. 2, p. 141-148, 1998. Disponível em: http://revista.ibict.br/ciinf/article/view/795/826. Acesso em: 20 ago. 2021. 
SWALES, John M. The concept of discourse community. In: SWALES, JohnM. Genre analysis. Cambridge: Cambridge University Press, 1990. p. 21-32. (Cambridge Applied Linguistics).

TOMAÉL, Maria Inês. Redes de conhecimento: o compartilhamento da informação e do conhecimento em consórcio de exportação do setor moveleiro. 2005. 289 f. Tese (Doutorado em Ciência da Informação) - Universidade Federal de Minas Gerais, Belo Horizonte, 2005. Disponível em: https://repositorio.ufmg.br/ handle/1843/EARM-6ZFQFX. Acesso em: 02 mar. 2021.

VALERIO, Palmira Moriconi; PINHEIRO, Lena Vania Ribeiro. Da comunicação científica à divulgação.

TransInformação, Campinas, v. 20, n. 2, p. 159-169, maio/ago., 2008. Disponível em: https://www.scielo.br/j/ tinf/a/jXWgggxgBhXfsT57JDVbghp/?lang=pt\&format=pdf. Acesso em: 20 ago. 2021.

VAN LEEUWEN, Thed N. et al. Language biases in the coverage of the Science Citation Index and its consequences for international comparisons of national research performance. Scientometrics, [s. I.], v. 51, n. 1, p. 335-346, 2001. DOI: https://doi.org/10.1023/A:1010549719484. Disponível em: https://link.springer. com/article/10.1023/A:1010549719484. Acesso em: 30 nov. 2021.

VANZ, Samile Andrea de Souza; STUMPF, Ida Regina Chittó. Colaboração científica: revisão teórico-conceitual. Perspectivas em Ciência da Informação, Belo Horizonte, v. 15, n. 2, p. 42-55, maio/ago. 2010. Disponível em: http://portaldeperiodicos.eci.ufmg.br/index.php/pci/article/view/1105/731. Acesso em: 26 fev. 2021.

VIACAVA, Francisco. Produção científica dos cursos de pós-graduação em saúde coletiva no período 1998-2006. Ciência \& Saúde Coletiva, Rio de Janeiro, v. 15, n. 4, p. 1977-1988, 2010. DOI: https://doi. org/10.1590/S1413-81232010000400013. Disponível em: http://www.scielo.br/pdf/csc/v15n4/a13v15n4. pdf. Acesso em: 03 mar. 2021.

WORLD HEALTH ORGANIZATION. Global Leprosy Strategy 2016-2020: accelerating towards a leprosyfree world: monitoring and evaluation guide. Nova Delhi: WHO; c2017. Disponível em: https://apps.who.int/ iris/bitstream/handle/10665/254907/9789290225492-eng.pdf?sequence=1\&isAllowed=y. Acesso em: 07 maio 2021.

WORLD HEALTH ORGANIZATION. Global leprosy (Hansen disease) update, 2019: time to step-up prevention initiatives. Weekly Epidemiological Record, Genebra, v. 95, n. 36, p. 417-440, 2020. Disponível em: https:// apps.who.int/iris/bitstream/handle/10665/334140/WER9536-eng-fre.pdf? sequence=1\&isAllowed=y\&ua=1. Acesso em: 26 fev. 2021.

WORLD HEALTH ORGANIZATION. Towards zero leprosy: global leprosy (Hansen's disease) strategy 20212030. Nova Delhi: WHO, c2021. Disponível em: https://www.who.int/publications///item/9789290228509. Acesso em: 07 maio 2021.

YANG, Siluo; WOLFRAM, Dietmar; WANG, Feifei. The relationship between the author by-line and contribution lists: a comparison of three general medical journals. Scientometrics, [s. I.], v. 110, n. 3, p. 1273-1296, 2017. DOI: https://doi.org/10.1007/s11192-016-2239-0. Disponível em: https://link.springer.com/article/10.1007/ s11192-016-2239-0. Acesso em: 30 nov. 2021.

YOUTIE, Jan; BOZEMAN, Barry. Social dynamics of research collaboration: norms, practices, and ethical issues in determining co-authorship rights. Scientometrics, [s. I.], v. 101, p. 953-962, 2014. DOI: https://doi. org/10.1007/s11192-014-1391-7. Disponível em: https://link.springer.com/article/10.1007/s11192-0141391-7. Acesso em: 13 dez. 2021. 